This item was submitted to Loughborough's Research Repository by the author.

Items in Figshare are protected by copyright, with all rights reserved, unless otherwise indicated.

\title{
Improving the abrasion resistance of "green" tyre compounds
}

PLEASE CITE THE PUBLISHED VERSION

https://doi.org/10.17265/1934-8975/2017.10.003

PUBLISHER

David Publishing

VERSION

AM (Accepted Manuscript)

PUBLISHER STATEMENT

This work is made available according to the conditions of the Creative Commons Attribution-NonCommercial 4.0 International (CC BY-NC 4.0) licence. Full details of this licence are available at: https://creativecommons.org/licenses/by-nc/4.0/

\section{LICENCE}

CC BY-NC 4.0

\section{REPOSITORY RECORD}

Zaeimoedin, Zakwan, and Jane Clarke. 2017. "Improving the Abrasion Resistance of "green" Tyre Compounds”. figshare. https://hdl.handle.net/2134/27438. 


\title{
Improving the Abrasion Resistance of "Green" Tyre Compounds
}

\author{
Teku Zakwan Zaeimoedin ${ }^{1,2}$ and Jane Clarke ${ }^{1}$ \\ 1. Department of Materials, Loughborough University, Loughborough LE11 3TU, United Kingdom \\ 2. RRIM Research Station, Malaysian Rubber Board, Sungai Buloh 47000, Selangor, Malaysia
}

Received: August 31, 2017 / Accepted: September 14, 2017 / Published: October 31, 2017

\begin{abstract}
Since the introduction of "green tyres" in the early 90's, the use of silica as a reinforcing filler, along with a silane coupling agent, has spread and grown worldwide. The greatest advantage of using silica over carbon black as reinforcing filler in a tyre tread compound is that a lower rolling resistance is achieved, while maintaining good wet traction. However, a previous study has shown that the wear resistance of a silica filled ENR (epoxidised natural rubber) compound was not as high as those of conventional OESBR (oil extended styrene butadiene rubber) and NR/BR compounds used in passenger car and truck tyre treads. In this work, with the aim of improving abrasion resistance, the effect of blending BR (butadiene rubber) into a silica filled ENR compound was studied. Blends with 0 to $30 \mathrm{phr}$ BR were prepared in a Polylab Haake internal mixer. The rheological properties of the compounds were measured using a Mooney viscometer and oscillating-disc rheometer. The hardness, tensile strength and DIN abrasion resistance were also measured. The results showed that the ENR/silica compound properties such as tensile strength and hardness were as good as those of the conventional compounds. However, the most important finding was that abrasion resistance increased significantly with BR content, exceeding that of the conventional compound at BR: ENR ratios of greater than 20:80.
\end{abstract}

Key words: ENR, BR, silica, abrasion resistance, tyre tread.

\section{Introduction}

The major advantages of a green tyre compound are having low rolling resistance, improved wet grip and enhanced handling [1]. It is reported that a 5\% decrease in rolling resistance is equivalent to a $1 \%$ saving in fuel, thus giving green tyres an economic benefit and consumer satisfaction. These green tyre properties can be achieved by utilizing silica as the main filler in the tyre tread compound. The first durable silica-filled tyre was introduced by Michelin and was also known as a green tyre [2].

Previous studies have found that silica has a poor interaction and dispersion especially in non-polar tyre rubbers compared to carbon black filler [3]. In contrast to carbon black, the surface of precipitated silica is highly polar and hydrophilic due to the presence of

Corresponding author: Teku Zakwan Zaeimoedin, Ph.D. student, research field: "green" tyre rubber compound. numerous silanol groups. As a result of the strong intermolecular hydrogen bonds between hydroxyl groups and relatively high surface area, agglomeration tends to occur during storage and the vulcanization process [4]. In order to improve the compatibility of silica with non-polar rubber and ensure its good coupling to the polymer matrix, the addition of coupling agents is necessary [5].

Silica with silane coupling agents have enabled tyre manufacturers to satisfy the "magic triangle of tyre properties" [6] where low rolling resistance of a tyre for fuel economy and improved wet grip for easy handling has been achieved while maintaining the abrasion resistance of the tyre (Fig. 1).

As a more economic alternative to using coupling agents it may be possible to use a modified form of natural rubber, ENR (epoxidised natural rubber), which gives better compatibility to silica, and higher reinforcement for silica compounds compared to 


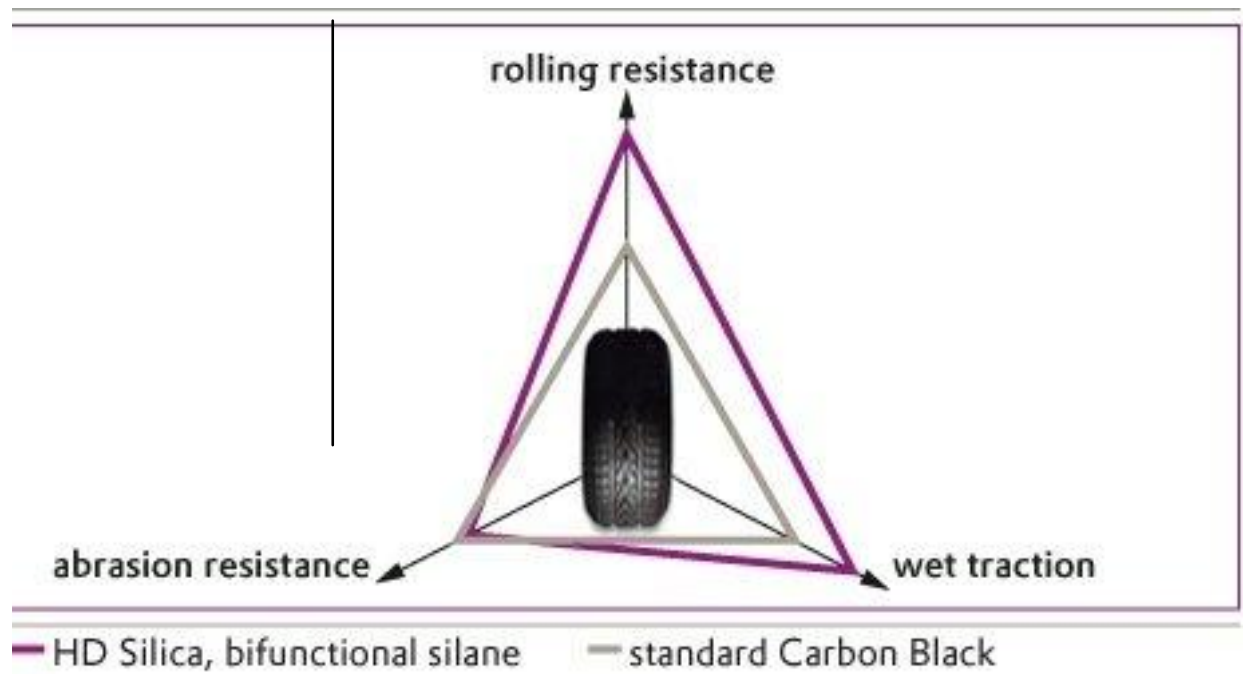

Fig. 1 Magic triangle of tyre properties.

natural rubber. The chemical modifications in ENR (epoxide groups) can react with the silanol group of silica, so that the use of coupling agents such as silane could be eliminated or greatly reduced [7]. In the 1980s, TARRC developed the first tread using silica-filled ENR-25 which provided improved wet grip and rolling resistance properties. However due to economic reasons and difficulties in mixing and processing of silica-filled ENR, the commercial uptake of this rubber in tyres was unattractive to tyre manufacturers. Furthermore, the wear result of ENR 25/silica compound was still not comparable to those OESBR (oil extended styrene butadiene rubber) and NR/BR compounds.

Today, increased environmental awareness, changes in economic factors and recent technical advances have made the use of silica filled ENR compounds for tyre manufacturing a viable option, especially for marketing as a green tyre product. The work reported in this paper aims to address the issue of relatively poor abrasion resistance of the ENR silica compound and determine the optimum amount of $\mathrm{BR}$ to add to significantly improve the abrasion properties.

\section{Materials and Methods}

\subsection{Materials}

The following polymers were used for this study:
$25 \%$ epoxidised natural rubber (EKOPRENA-25) and standard Malaysian rubber (SMR 10) supplied by the Malaysian Rubber Board. The fillers used for this study include: conventional precipitated silica filler (Zeosil 1165 MP) supplied by Solvay and Carbon Black N330 supplied by Orion. The X50S silane coupling agent was supplied by Evonik Industries. The others chemicals such as zinc oxide, stearic acid, antioxidant and rubber accelerators were commercial grade rubber chemicals. The compound formulations were used to assess the effect of Butadiene rubber loading on the properties of silica filled ENR/BR blends. The compound formulation is based on a typical truck tyre tread formulation. The formulations and materials used in this study are given in Table 1.

\subsection{Mixing}

In this work, all the mixing of the compounds was carried out in three stages in a Polylab OS Hake Rheomix 3000 fitted with Banbury rotors and with a $379 \mathrm{~cm}^{3}$ chamber volume. Silica and carbon black were added in 2 portions to improve incorporation. The silica was divided into $2 / 3$ and $1 / 3$ portions. The X50S was also divided into $2 / 3$ and $1 / 3$ portions and was pre blended with $2 / 3$ silica and $1 / 3$ silica filler, respectively prior to mixing. In the first stage of mixing, a 0.6 fill factor, $70 \mathrm{rpm}$ of rotor speed and starting 
Table 1 Formulations of silica filled ENR, ENR/BR and carbon black filled NR/BR compound.

\begin{tabular}{|c|c|c|c|c|c|c|}
\hline Ingredients & Mix 1 & Mix 2 & Mix 3 & Mix 4 & Mix 5 & Mix 6 \\
\hline ENR-25 & 100 & 100 & 90 & 80 & 70 & \\
\hline SMR 10 & & & & & & 70 \\
\hline BR 40 & & 0 & 10 & 20 & 30 & 30 \\
\hline Silica Zeosil 1165MP & 55 & 55 & 55 & 55 & 55 & \\
\hline N330 Black & 5 & 3 & 3 & 3 & 3 & \\
\hline N234 Black & & & & & & 53 \\
\hline Zinc oxide & 3 & 3 & 3 & 3 & 3 & 3.5 \\
\hline Stearic acid & 3 & 3 & 3 & 3 & 3 & 2.5 \\
\hline Calcium stearate & 2 & 2 & 2 & 2 & 2 & \\
\hline Antioxidants & 2 & 2 & 2 & 2 & 2 & 3.5 \\
\hline Antilux 654 & 1 & 1 & 1 & 1 & 1 & 1 \\
\hline X50S (50\% Si69 on CB) & - & 4.4 & 4.4 & 4.4 & 4.4 & \\
\hline Sulphur & 0.7 & 0.7 & 0.7 & 0.7 & 0.7 & 1.2 \\
\hline Accelerators & 1.75 & 1.75 & 1.75 & 1.75 & 1.75 & 1 \\
\hline Silane Si69 & 1 & 1 & 1 & 1 & 1 & \\
\hline
\end{tabular}

Table 2 Standard methods used for physical and mechanical property tests.

\begin{tabular}{ll}
\hline Physical \& Mechanical properties test & Standard method \\
\hline Tensile strength & BS ISO 37:2011 \\
Hardness (IRHD) & MS ISO 48:2010 \\
DIN abrasion resistant index & ISO 4649:2002 \\
\hline
\end{tabular}

temperature of $80{ }^{\circ} \mathrm{C}$ were employed. The dumping time was set for 3 minutes after the indicated temperature reached $140{ }^{\circ} \mathrm{C}$. Later, the masterbatches were sheeted out on a warm two-roll mill with minimal passes. In the second stage, the masterbatches were remilled in the same mixer for 3 minutes with a rotor speed of $80 \mathrm{rpm}$ and starting temperature of $80{ }^{\circ} \mathrm{C}$. Then the masterbatches were sheeted out on warm two-roll mill with minimal passes. Finally, the mixing was completed in 2 minutes of mixing when the curative agents were added, with a mixer temperature and rotor speed of $40{ }^{\circ} \mathrm{C}$ and $50 \mathrm{rpm}$ respectively. Then the compounds were sheeted out on a warm two-roll mill with minimal passes.

\subsection{Mooney Viscosity}

Mooney viscosity measurements were carried out using a Wallace MKIII viscometer at $100{ }^{\circ} \mathrm{C}$. The sample weights were in the range of 25-30 g. The Mooney viscosity was recorded for compounds at the masterbatch, remill and finalised stage. The testing was conducted based on the ISO 289-1 standard.

\subsection{Cure Characteristics}

The curing properties of the compound samples were assessed at $150{ }^{\circ} \mathrm{C}$ and 30 minutes, using a Monsanto MDR 2000 rheometer with $3^{\circ}$ arc based on the ISO 6502 standard.

\subsection{Physical and Mechanical Properties}

The physical and mechanical properties tested were conducted according to standard methods as tabulated in Table 2.

\section{Results and Discussion}

\subsection{Mooney Viscosity}

The Mooney viscosity of masterbatches and final compounds of ENR/silica and ENR/BR mixes based on truck tyre tread compounds with addition of coupling agents are shown in Table 3. It was found that ENR/silica with silane coupling agent (Mix 2) gave a lower masterbatch, and final compound Mooney 
viscosity compared to the ENR control compound. The $\mathrm{NR} / \mathrm{BR}$ compound which is a conventional truck tyre tread formulation still gave the lowest Mooney viscosities for both masterbacth and final compound. Usually lower Mooney viscosity is an indirect indication of good processability and flow properties due to lower elastic energy of rubber mix. It can be said that the presence of coupling agent during mixing of ENR/silica improved the processability and flow properties of the compounds by reducing their viscosity and elastic energy. It can be observed that the Mooney viscosity of ENR/BR blends increased as the BR percentage in ENR increased. This is because the viscosity of the Butadiene rubber remains relatively constant during mixing, because it was less affected by the mastication than the ENR which decreases in viscosity during mixing.

\subsection{Cure Characteristics}

The rheometer curves and cure characteristics of ENR/silica and ENR/BR blend compounds are presented in Fig. 2 and Table 4 respectively. It can be observed that the ENR/silica compound that contains X50S silane coupling agent (Mix 2) exhibits a higher $\Delta$ torque value $\left(\mathrm{M}_{\mathrm{H}}-\mathrm{M}_{\mathrm{L}}\right)$ than the ENR/silica control compounds (Mix 1). This may be expected since the reacted coupling agent will contribute to the crosslinks in the cured compound. Mix 2 also gave a lower $M_{L}$ than Mix 1, which is in agreement with the earlier results showing Mix 2 having the lowest Mooney viscosity.

Table 3 Mooney viscosity of ENR/silica and ENR/BR blends.

\begin{tabular}{lllllll}
\hline \multirow{2}{*}{ Mooney viscosity } & Mix 1 & Mix 2* & Mix 3* & Mix 4* & Mix 5* & Mix 6 \\
\cline { 2 - 7 } & ENR control & ENR100:BR0 & ENR90:BR10 & ENR80:BR20 & ENR70:BR30 & NR70:BR30 \\
\hline Masterbatch & 144 & 111 & 116 & 138 & 157 & 90 \\
Final compound & 80 & 69 & 76 & 90 & 97 & 63 \\
\hline
\end{tabular}

* Added X50S during mixing.

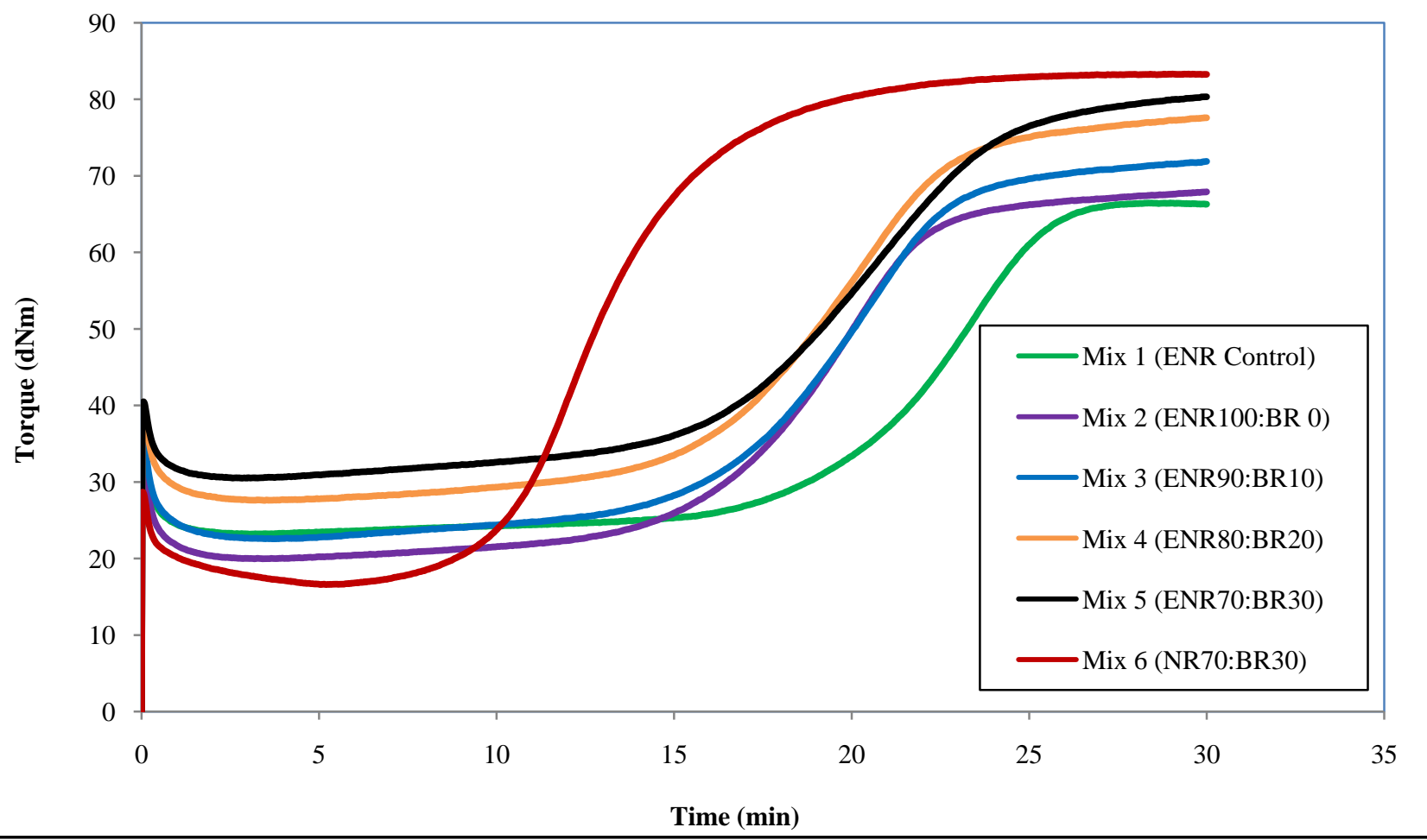

Fig. 2 Rheometer curves of ENR/silica and ENR/BR blend compounds. 
Table 4 Rheometer and curing characteristics of ENR/silica and ENR/BR blend compounds.

\begin{tabular}{lllllllll}
\hline Mix & $\mathrm{M}_{\mathrm{L}}$ & $\mathrm{M}_{\mathrm{H}}$ & ts1 & ts2 & t90 & t95 & $\mathrm{M}_{\mathrm{H}}-\mathrm{M}_{\mathrm{L}}$ & Torque at 30 min \\
\hline No & $(\mathrm{dNm})$ & $(\mathrm{dNm})$ & $(\min \mathrm{sec})$ & $(\min : \mathrm{sec})$ & $(\mathrm{min}: \mathrm{sec})$ & $(\mathrm{min}: \mathrm{sec})$ & $(\mathrm{dNm})$ & $(\mathrm{dNm})$ \\
\hline 1 & 23.19 & 66.46 & $9: 13$ & $14: 38$ & $25: 15$ & $25: 36$ & 43.27 & 66.30 \\
2 & 19.97 & 67.92 & $8: 08$ & $11: 07$ & $22: 25$ & $23: 48$ & 47.95 & 67.92 \\
3 & 22.58 & 71.90 & $7: 26$ & $10: 24$ & $23: 07$ & $24: 48$ & 49.32 & 71.90 \\
4 & 27.60 & 77.62 & $7: 56$ & $10: 40$ & $23: 14$ & $25: 03$ & 50.02 & 77.61 \\
5 & 30.51 & 80.34 & $6: 49$ & $9: 48$ & $24: 26$ & $26: 01$ & 49.84 & 80.34 \\
6 & 16.60 & 83.32 & $7: 12$ & $8: 04$ & $17: 37$ & $19: 41$ & 66.72 & 83.27 \\
\hline
\end{tabular}

Table 5 Physical properties of ENR/silica and ENR/BR blend compounds.

\begin{tabular}{lllllll}
\hline \multirow{2}{*}{ Properties } & Mix 1 & Mix 2* & Mix 3* & Mix 4* & Mix 5* & Mix 6 \\
\cline { 2 - 7 } & ENR control & ENR100:BR0 & ENR90:BR10 & ENR80:BR20 & ENR70:BR30 & NR70:BR30 \\
\hline Tensile strength, MPa & 20.2 & 23.4 & 22.7 & 24.2 & 23.3 & 26.8 \\
Elongation @ break, \% & 429 & 434 & 419 & 495 & 513 & 573 \\
Modulus, M100 & 1.6 & 2.1 & 2.4 & 2.3 & 2.3 & 2.2 \\
MPa & 63 & 63 & 64 & 66 & 69 & 72 \\
Hardness (IRHD) & 98 & 139 & 183 & 227 & 163 \\
DIN abrasion resistant & 80 & 98 & & & & \\
Index, $\%$ & & & & & & \\
\hline
\end{tabular}

* Added X50S during mixing.

This could be due to the coupling agent helping to reduce viscosity by reducing silica: silica interactions. The higher crosslink density of ENR/silica compound containing X50S silane coupling agent (Mix 2) is in agreement with the physical properties of this compound that shows they have higher tensile strength and hardness properties than Mix 1 (Table 5). This is expected due to the coupling agent effectively crosslinking the silica filler to the rubber matrix, increasing the interaction between silica and rubber and effectively increasing crosslink density.

NR/BR compounds (Mix 6) still gave the highest values of $\Delta$ torque as compared to all compounds as well as the lowest $\mathrm{M}_{\mathrm{L}}$ value among all compounds.

For the ENR/BR blend compounds, the results showed that torque values increase with increase in BR content. These higher values of torque indicate these compounds have higher stiffness than ENR/silica compounds which is in agreement with the Mooney viscosity results as discussed earlier.

\subsection{Physical and Mechanical Properties}

The physical and mechanical properties of ENR/silica and ENR/BR compounds are shown in
Table 5. From these results, it is observed that ENR/silica vulcanizates containing X50S silane coupling agent (Mix 2) exhibit slightly higher properties of tensile strength, elongation at break, hardness and abrasion resistance index as compared to ENR/silica control compound (Mix 1). This is probably due to the better rubber-filler interaction and crosslink network in ENR/silica compounds with the presence of X50S coupling agent.

Table 4 also shows that most properties are not significantly affected by the BR content of the ENR/BR blends. However, there is a slight increase in hardness and a significant increase in DIN abrasion resistance with increase with BR content. The increase in hardness is in agreement with rheometer curves which showed an increase in maximum torque with increase in BR content. It is interesting to note that the DIN abrasion resistance index of Mix 5 is higher than that of the NR/BR vulcanizate, which will be very valuable in the development of a new tyre tread compound.

\section{Conclusions}

For processing and cure characteristics, the Mooney 
viscosity and maximum torque increased with the increasing BR content in silica filled ENR compounds. Silica filled ENR/BR compounds with silane coupling agent also exhibit good hardness and tensile strength properties compared to carbon black filled NR/BR compound (conventional truck tyre tread compound). The results have shown that abrasion resistance increases with BR content and had surpassed the abrasion resistance of conventional carbon black filled NR/BR compound at ENR80:BR20 blend ratio. Hence, addition of even a relatively small amount of BR into the ENR/silica compound will allow the abrasion resistance to match that of the conventional NR/BR compound.

\section{Acknowledgements}

The authors would like to thank the Department of Materials, Loughborough University for the research facilities provided and also Malaysian Rubber Board for the sponsor and support in carrying out this project.

\section{References}

[1] Ita, P. A. 2005. "Filler Requirements in the Tire Industry: Carbon Black \& Precipitated Silica." Tire Technology
Expo \& Conference, Koln Messe, Cologne, Germany.

[2] Dinkel, J. 1995. "Where the Silica Meets the Road." Discover. [Online]. Available: http://discovermagazine.com/1995/apr/wherethesilicame4 97.

[3] Wang, M. J. 2008. "Billerica, Effect of Filler-Elastomer Interaction on Tire Tread Performance Part II." Raw Materials and Applications, 33-42.

[4] Kaewsakul, W., Sahakaro, K., Dierkes, W. K., and Noordermeer, J. W. M. 2014. "Flocculation Kinetics and Filler-Rubber Interaction in Silica-Reinforced NR Compounds." 186th Technical Meeting of Rubber Division, ACS, Nashville, TN, October 2014.

[5] Gerster, M., Fagouri, C., and Peregi, E. 2010. "Novel Coupling Agents for Silica-Filled Rubbers with Superior Processing Safety and Improved Hysteresis of the Vulcanizates." Tire Science and Technology 38 (1): 80-98.

[6] The "Magic triangle" of Car Tires. [Online]. Available: http://www.rubber-silanes.com/product/rubber-silanes/en/ effects/magic-triangle/pages/default.aspx.

[7] Cataldo, F. 2002. "Preparation of Silica-Based Rubber Compounds without the Use of a Silane Coupling Agent through the Use of Epoxidized Natural Rubber." Macromolecular Materials and Engineering 287 (5): 348-52.

[8] Gelling, I. R. 1991. “Epoxidised Natural Rubber.” Journal of Natural Rubber Research 6 (3): 184-205. 